\title{
FOLHAS VOLÁTEIS, PAPÉIS MANUSCRITOS: O PELOTÃO DE SAÚDE NO JORNAL INFANTIL PÉTALAS (COLÉGIO CORAÇÃO DE JESUS - FLORIANÓPOLIS/SC, 1945-1952)
}

\author{
Maria Teresa Santos Cunha \\ Universidade do Estado de Santa Catarina, Brasil.
}

\begin{abstract}
Resumo
O jornal Pétalas Infantil era uma produção manuscrita, feita em folhas avulsas, realizada pelas alunas do curso primário do Colégio Coração de Jesus, uma instituição religiosa e feminina de Florianópolis/SC, e cujos exemplares, entre 1945 e 1952, foram conservados em um acervo pessoal. O texto deste estudo centra-se na análise dos artigos e comentários que expressavam preceitos veiculados pelo pelotão de saúde, uma associação complementar da escola, legitimada por lei e cujo propósito era auxiliar na criação e manutenção de princípios higiênicos como integrantes da cultura escolar do período. O artigo vincula-se ao campo de pesquisa da História da Educação e da cultura escrita entendidas, ambas, como produções discursivas e escolares de um determinado tempo e lugar que, tanto pelos suportes em que se apresentam à leitura, como pelos preceitos higienistas e cívicos que punham em circulação, permitem pensar a importância desse material na construção de uma memória para o reconhecimento de diferentes práticas, costumes, rituais, ações que integravam o ambiente escolar do período em pauta.

Palavras-chave: jornal infantil, pelotão de saúde, higiene e cultura escolar.
\end{abstract}

\section{VOLATILE SHEETS, MANUSCRIPT PAPERS: THE PLATOON OF HEALTH IN PETALS CHILDISH JOURNAL (COLÉGIO CORAÇÃO DE JESUS - FLORIANÓPOLIS/SC, 1945-1952)}

\begin{abstract}
Petals Childish journal was a handwritten production, made in single sheets of paper, held by the students of the primary school Coração de Jesus, a religious institution for girls in Florianópolis/SC and who's exemplary, between 1946 and 1952, were kept in a personal collection. This study focused on the analysis of the articles and comments that expressed precepts conveyed by the platoon of health, a complementary association of the school, legitimized by law, and whose purpose was to assist in the creation and maintenance of hygienic principles as part of the school culture of the period. The article connects to the search field of the history of education and education's history, both understood as writing discursive and school productions of a determined time and place that, as much by the stand in with it is presented to reading, as much
\end{abstract}


as by the hygienist and civic precepts it laid in circulation, allow you to think of the importance of this material in the construction of a memory for the recognition of different practices, customs, rituals, actions that were part of the school ambient of the period.

Key-words: childish journal, platoon of health, hygiene and school culture.

\title{
HOJAS VOLÁTILES, PAPELES MANUSCRITOS: EL PELOTÓN DE SALUD EN PERIÓDICO PÉTALAS (COLÉGIO CORAÇÃO DE JESUS - FLORIANÓPOLIS/SC, 1945-1952)
}

\begin{abstract}
Resumen
El periódico Pétalas era un manuscrito producido por los niños, realizada en una sola hoja, celebrada por los alumnos de la escuela primaria del Sagrado Coração de Jesus, una institución religiosa y la hembra de Florianópolis/SC y cuyo ejemplar, entre 1946 y 1952, se mantuvieron en una colección personal. Este estudio se centró en el análisis de los artículos y comentarios que expresó preceptos transmitidos por el pelotón de salud, una asociación de escuela, legitimada por la ley, y cuyo propósito era ayudar en la creación y mantenimiento de los principios higiénicos como parte de la cultura escolar del período. El artículo se vincula con el campo de búsqueda de la historia de la educación y la cultura escrita, tanto como escritura entendían discursiva y producciones de la escuela de una determinada hora y lugar que tanto por los soportes en se presentan en la lectura, por cívicos y preceptos higienistas que puso en movimiento, permiten pensar en la importancia de este material en la construcción de una memoria de reconocimiento de las diferentes prácticas, costumbres, rituales, actos que fueron parte del ambiente escolar del período.

Palabras-clave: diario infantil, pelotón de la salud, la higiene y la escuela.
\end{abstract}

\author{
FEUILLES DE VOLATILES, PAPIER MANUSCRITS: \\ LE JOURNAL SANTE POUR ENFANTS PETALAS \\ (COLÉGIO CORAÇÃO DE JESUS - FLORIANÓPOLIS/SC, 1945-1952)
}

\section{Résume}

Le jounal Pétalas pour enfants était un manuscrit faite dans une feuille unique, tenu par les élèves de l'école primaire du Sagrado Coração de Jeses, une institution religieuse et femalle de Florianópolis/SC; leurs exemplaires, pendant les annés de 1946 et 1952, étaient conservés dans une collection personnelle. Cette étude a porté sur l'analyse des articles et des commentaires qui expriment les préceptes transmis par le peloton de la santé, une association de l'école, légitimé par la loi, et dont le fonction est d'aider à la création et au maintien des principes de l'hygiène dans le cadre de la culture de l'école de la période. L'article est situé vers le champ de recherche de I'histoire de l'éducation et la culture écrit, et enténd les deux comme écriture discursive et productions de l'école d'un particulier temps et lieu qui, pour les prend en charge que se présentent à la lecture, pour civique et préceptes hygiénistes mis en mouvement, nous permettent de penser que l'importance de ce materiél dans la construction d'une mémoire pour la reconnaissance des différentes pratiques, les rituels, les actions qui faisaient partie du milieu de la période scolaire.

Mots-clé: journal des enfants, peloton de la santé, l'hygiène et l'école. 


\section{Introdução: os dizeres do jornal Pétalas Infantil}

Aos 10 de março de 1946, em sessão solene, foram reiniciados os trabalhos do Clube Osvaldo Cruz, nosso Pelotão de Saúde, que visa despertar o interesse pela Saúde, Higiene e Estética. [...] Todas as sócias renovaram o propósito de se dedicar com zelo e carinho ao cumprimento da divisa de nosso Clube Pró-Sáude, Higiene e Estética. (Pétalas Infantil, set., 1945)

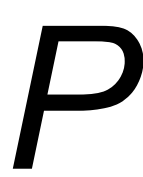

étalas Infantil, criado em $1943^{1}$ e com circulação até 1952, era o jornal escolar produzido pelas meninas e alunas do curso primário do Colégio Coração de Jesus, em Florianópolis/SC, e que recebia o mesmo nome da revista oficial do Colégio - Pétalas. ${ }^{2}$ Todo feito à mão, apresentado em folhas de papel almaço avulsas e não numeradas, o periódico ostentava como subtítulo o adjetivo infantil e assim foi legitimado como o suplemento infantil do Colégio Coração de Jesus. Dele participavam alunas com idade entre sete e dez anos. Esse jornal manuscrito tinha por propósito divulgar as atividades escolares desenvolvidas pelas alunas desse estabelecimento de ensino religioso feminino, que atendia a elite florianopolitana e era dirigido pelas irmãs da Divina Providência ${ }^{3}$. O título do jornal, Pétalas, que significa cada uma das peças que constituem a corola das flores, foi criado em 1933 pela irmã Benwarda, então diretora geral do Colégio e sinaliza para uma visão idealizada que pode ser vista na própria justificativa:

Foi esta a minha intenção, ao idear nosso modesto periódico, depor uma pétala de alegria nos corações de minhas boas alunas, verdadeiras flores que ornamentam nossos jardins, as quais envio as minhas saudades e um cordial agradecimento. (irmã Benwarda, Revista Pétalas, n. 1, 1933)

Adjetivado como infantil pretendia, em suas páginas, ser a expressão das diversas vivências e impressões das alunas e do colégio. Priorizava-se as atividades discentes e sua circulação era restrita à própria comunidade escolar, haja vista sua produção única. Pela organização e pelo conteúdo veiculado, tudo indica que sua produção tinha a aquiescência e era revisado pela direção da escola, pois que atendia a preceitos legislativos vigentes à época. Em suas páginas é possível encontrar, em perfeita expressão escrita, notícias sobre o cotidiano escolar, colaborações das alunas - poesias, redações escolares, notícias de viagens realizadas pela escola -, descrições pormenorzadas sobre comemorações escolares, acontecimentos sociais: uma espécie de crônica da vida estudantil, ações que oferecem um sentido para se conhecer aspectos do projeto educativo daquela instituição escolar.

\footnotetext{
${ }^{1}$ Não tive acesso aos exemplares dos anos de 1943 e 1944.

2 A Revista Pétalas foi um impresso educacional do Colégio Coração de Jesus, em Florianópolis/SC, criado em 1933 e publicado semestralmente até 1964, mantido pelas alunas dos cursos ginasial e normal.

${ }^{3}$ Ordem religiosa alemã que chegou em Santa Catarina nos finais do século 19 e fundou o referido colégio em 1898. Até 2004 foi mantido por esta Congregação e abrigava as filhas da elite catarinense, entendida aqui na perspectiva de Heinz (2006, p. 7) como a que faz referência "a categorias ou grupos que parecem ocupar o topo de estruturas de autoridade ou de distribuição de recursos [...] os chamados dirigentes, pessoas influentes, abastados ou privilegiados". Atualmente, o Colégio pertence à rede Bom Jesus.
} 
Das páginas do jornal Pétalas Infantil, o presente estudo selecionou aqueles escritos que estabelecem uma relação entre higiene e educação, refletindo sobre a presença, no Colégio Coração de Jesus, dessa associação complementar da escola, conhecida como Pelotão de Saúde, cujas ações estão descritas no período entre 1946 e 1952. Os pelotões de saúde, legalmente formados e respaldados pela legislação escolar ${ }^{4}$, foram instituições que auxiliavam na manutenção da higiene dentro das escolas, tendo em vista o asseio pessoal dos alunos e a prevenção de doenças em uma sociedade que se urbanizava.

O corpus documental disponível para consulta é composto por 66 exemplares do periódico, que foram produzidos mensalmente entre 1945 e 1952. Foram fotocopiados e estão digitalizados em meu acervo pessoal. Trata-se de coleção que foi conservada pela devoção filial de quem não queria se desfazer desses papéis relíquia, ainda que ordinários. É uma possibilidade de, por meio do estudo de uma revista escolar periódica, compreender como "a imprensa pedagógica constitui-se em um dispositivo privilegiado para a reflexão sobre o modo de produção de discursos" (Bastos, 1997, p. 73) e, ao mesmo tempo, reconhecer aspectos que criam possibilidades para conhecimento da cultura material escolar brasileira.

As questões higiênicas ligadas à educação física, moral e intelectual das crianças, em geral ou no ambiente dos colégios, eram as que mais absorviam a atenção dos educadores. Os estudos de Rosa Fátima de Souza (1998) mostram que, desde os inícios do século 20 , a aplicação das noções científicas, especialmente àquelas relacionadas à higiene, consubstanciavam o ideal de ordenação do universo urbano no Brasil e marcaram presença no ambiente escolar. Dessa forma, a escola vinculava-se às estratégias e saneamento dos espaços públicos e marcava sua inserção duradoura nos projetos médico-pedagógicos de higienização social.

A importância da era da higiene na escola primária é, igualmente, registrada nos estudos de Heloisa Helena Pimenta Rocha (2000) para quem, desde as décadas iniciais do século 20, variados dispositivos utilizados nas escolas contribuíram para uma persuasão do leitor em torno da fixação de um conjunto de hábitos de higiene, muitas vezes associados ao civismo, voltados para a preservação da saúde individual e coletiva na educação escolarizada.

A criação e divulgação de preceitos higiênicos no jornal escolar Pétalas Infantil não se distanciava disso e sua elaboração, pelas alunas, visava a evidenciar, nesses moldes, a participação discente no próprio cotidiano da escola e, mais ainda, a observância aos princípios legais que regiam a educação em Santa Catarina.

Pode-se considerar, igualmente, que os colégios contribuíram para a intensificação do movimento higiênico e que foram impulsionados pelas prescrições legislativas que forçavam inserções curriculares dessa ordem, na qual os jornais escolares representavam uma estratégia de divulgação para a medicalização do espaço urbano. Segundo Jurandir Freire Costa (1999, p. 180), "no micro universo dos colégios, a higiene antevia a sociedade ideal e o novo homem e a nova sociedade começariam a serem construídos no colégio", que funcionava como propagador das regras de formação do corpo sadio do adulto e da consciência nacionalista plasmada na idade infantil.

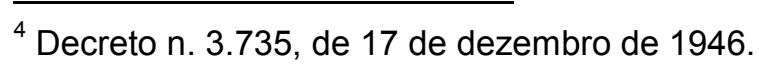


Ainda que menos visitadas pela investigação histórica, estas práticas de escritas escolares e infantis são formas de produção cultural e documentos importantes em que se pode fazer confluir os interesses da História da Educação com a história da cultura escrita. ${ }^{5}$ A História da Educação se abre aos objetos escritos, que põem em cena procedimentos e práticas metodológicas experimentadas em sala de aula e fora dela ${ }^{6}$. A história da cultura escrita, por sua vez, ao interessar-se pelos aspectos gráficos, cria condições para se entender os diferentes níveis de alfabetização, a materialidade das escritas escolares, a forma como jovens alunas de apropriavam da tecnologia gráfica para representar o que aprendiam, conheciam e experimentavam (Castillo; Blass, 2008).

\section{Jornal Pétalas Infantil: a lápis e em cores}

A produção e circulação do jornal Pétalas Infantil (1943-1952), marca o período final da Segunda Guerra Mundial e o início do processo de redemocratização da sociedade brasileira, após Getúlio Vargas. Este período está identificado na política educacional, em nível nacional, com a promulgação da Lei Orgânica do Ensino Normal, em 1946, e a intensificação dos debates em torno dos novos rumos políticos, culturais e educacionais. No âmbito regional, o ano de 1946 coincide com a promulgação da Lei Orgânica do Ensino Primário no Estado de Santa Catarina (decreto-lei n. 298/46), também conhecida como Reforma Elpídio Barbosa7, complementada pelo Regulamento para os Estabelecimentos de Ensino Primário no Estado de Santa Catarina, instituído pelo decreto-lei n. 3.735, de 17 de dezembro de 1946.

A consulta à legislação educacional do Estado de Santa Catarina permite afirmar que a preocupação em legitimar as associações complementares da escola já se encontrava pautada desde 1943, como expressa o decreto-lei estadual n. 2.991, de 28 de abril de 1944, assinado pelo diretor do Departamento de Educação, professor Elpídio Barbosa. Este considerava importante a difusão dessas associações nas escolas como parte de um projeto educativo mais amplo que, em síntese, contribuísse para a formação de uma infância que reverberasse em futuros cidadãos saudáveis e úteis à nação brasileira:

Por intermédio das associações bem orientadas, colocaremos a Escola nos moldes compatíveis à evolução, que a vida experimenta, visto ser a fonte preparadora das gerações em caminho de um plano melhor, condizente com a nossa civilização (Santa Catarina, 1944, p. 1).

\footnotetext{
${ }^{5}$ Esta abordagem vem sendo realizada pelo grupo liderado por António Castillo Gómez e Verônica Sierra Blas que lançaram, recentemente, uma coletânea de estudos intitulada Mis primeros passos: alfabetización, escuela y usos cotidianos de la escritura (siglos 19 y 20), (2008). Para eles, "história da cultura escrita é o estudo da produção, difusão, uso e conservação dos objetos escritos, [...] para isso busca alianças com quantos saberes, como os advindos da história da educação escolarizada, que tem como seu objeto o estudo da escrita em suas várias modalidades" (p. 19). Ver também Castillo Gómes (2002).

6 Refiro-me, especialmente, aos estudos realizados e coordenados por Ana Chrystina Venancio Mignot (2008) e António Vinão Frago (2002).

7 Elpídio Barbosa (1909-1966) foi uma figura importante no meio educacional catarinense, sendo inspetor escolar (1931-1934), técnico do Departamento de Educação de Santa Catarina (1935-1940) diretor-geral do Departamento de Educação (1940/1951); inspetor geral do Ensino Normal (1950) orientador pedagógico do Sesc em Santa Catarina (1955); membro do Conselho Diretor da Fundação da Udesc (1957); secretário de Estado da Educação e Cultura (1963-1965), presidente do Conselho Estadual de Educação (1963), (Fiori, 1991).
} 
Mantinha-se, ainda nesse período, o que Marta Carvalho (1998) escreveu sobre as primeiras décadas do século: "saúde, educação e trabalho eram os três pilares principais sobre os quais se assentava a convicção a respeito da importância da educação" (p. 148). O primeiro pilar refere-se à preocupação sanitarista, à higienização; o segundo com o controle da vadiagem, os distúrbios oriundos das disputas e tensões entre as classes, e o terceiro, o propulsor da tão desejada modernização.

Estes dispositivos legais e considerados científicos estavam mais afinados com os pressupostos dos princípios escolanovistas, notadamente ao legislar sobre a organização escolar, como a obrigatoriedade do funcionamento das instituições complementares da escola que eram, seguindo a ordem expressa na legislação, a liga pró-língua nacional, biblioteca, o jornal escolar, o clube agrícola, o círculo de pais e professores, os museus escolares, os centros de interesses, a liga da bondade, o clube de leitura e o pelotão de saúde. Estas iniciativas ecoaram em políticas geradas sob a insígnia de um Brasil moderno e laico, bem como reforçaram investimentos escolares em atividades práticas sobre a importância da higiene e dos bons costumes no cotidiano.

O Pelotão de Saúde também se fez presente no Rio Grande do Sul e suas atividades mereceram destaque na Revista de Ensino. Em 1952, a notícia ali veiculada informava que

no Grupo Escolar Paulo da Gama (POA) funciona junto ao gabinete médico-dentário, o Pelotão da Saúde, "instituição altamente educativa, pelos princípios que tem em vista, assim como pelos meios desenvolvidos para atingir suas finalidades [...] realiza, também, uma sessão literária, onde os temas abordados visam a moral, a higiene física e mental, como educação cívica, sob a forma de palestras, composições, poesias declamações ou lidas, leitura de preceitos concernentes aos assuntos de interesse, citação de exemplos reais, observados pelos monitores". (Revista do Ensino/RS, maio, 1952, n. 6, p. 55)

\section{Pétalas: o suporte}

O corpus documental utilizado para este trabalho é composto de uma coleção do jornal Infantil Pétalas, que abrange os anos de 1945 a 1952. Em cada ano, publicavam-se nove exemplares, entre os meses de março a novembro, com um total de 66 exemplares produzidos no período. Cada jornal tinha entre seis a oito páginas e era escrito em folhas, em sua maioria pautadas, de papel almaço comum. A capa trazia, em letras maiúsculas, o nome do periódico, sempre em formato manuscrito, em letras de imprensa milimetricamente iguais, secundado por desenhos feitos pelas próprias alunas. 
Figura 1

Capa da Revista Pétalas Infantil, 1947.

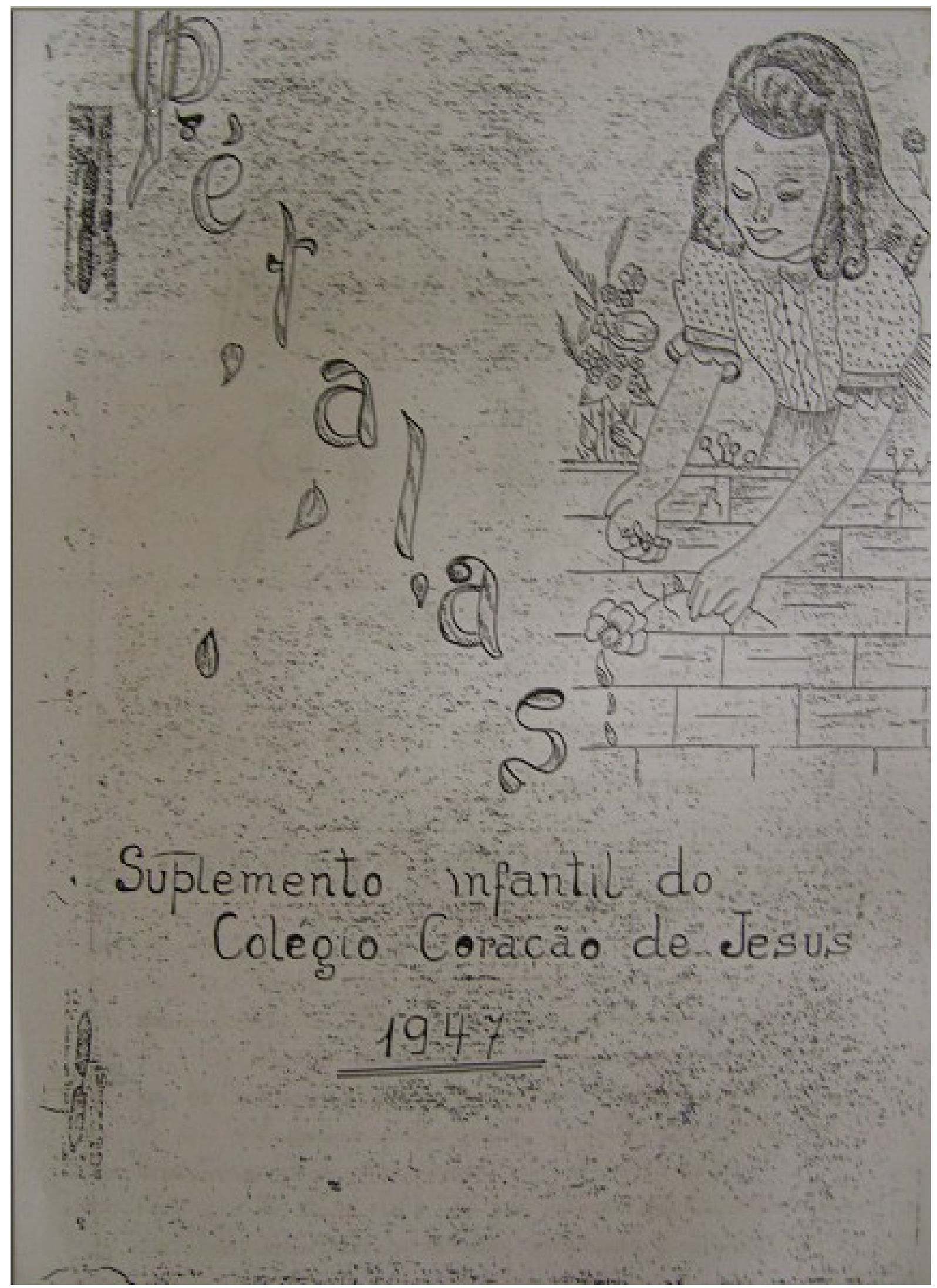

Fonte: Acervo da autora. 
Combinado aos desenhos, atrela-se uma série de recursos gráficos, como o título da publicação inclinado, o contorno das letras, a cor e o tamanho usado, a data, o desenho de pétalas em queda e, em alguns casos, o nome da diretora-gerente sempre ao lado esquerdo, em posição de destaque. Todas estas referências formam um protocolo de leitura: sugerem uma leitura, constroem significados e são considerados na clave da cultura escrita como "uma fórmula editorial que dá ao objeto formas próprias, que organiza os textos de acordo com dispositivos gráficos específicos" (Chartier, 1989, p. 178).

No jornal Pétalas, publicado em agosto de 1952, há o registro da visita do inspetor de ensino, professor Américo Vespúcio Prates, que elogiou a instituição e fez referência à excelência da escrita clara e disciplinada das alunas responsáveis pelo periódico, como uma experiência ligada à caligrafia muscular. $O$ uso desses termos técnicos relativos à caligrafia mobiliza bases para uma reflexão a partir dos estudos de Gvirtz e Vidal (1998), que se referem às experimentações sobre caligrafia muscular realizadas por Orminda Marques, entre 1933 e 1936, na escola primária do Instituto de Educação do Distrito Federal (RJ), segundo a qual com este tipo de escrita "pretendia-se construir uma didática racional da escrita [...] como expressão do pensamento que oferecesse aos alunos uma técnica de otimização do traçado da letra: legibilidade, clareza, velocidade e elegância" (Ibid., p. 23).

Os estudos sobre ensino da escrita e da leitura realizados por Eliane Peres (2003) no Rio Grande do Sul mostram "as relações que se estabeleciam com o ato de escrever: escrita-saúde, escrita-corpo, escrita-postura" (p. 89) e ratificam o pressuposto desse estudo: pelo controle gráfico buscava-se uma construção de boas posturas físicas, bons comportamentos e boas maneiras.

Primando pela caligrafia esmerada, visível na boa disposição das letras e dos desenhos das próprias alunas, evidenciavam-se materialidades associadas a objetos de uso escolar, tais como lápis apontados, réguas para garantir a linearidade da escrita, canetas-tinteiro, cola, recortes, lápis de cor. A confecção desse pequeno jornal faz supor a presença da coordenação corporal e motora na escola e, especialmente, de atitudes como atenção e concentração nas práticas de escrita, já que um corpo disciplinado para a escrita exigia gestos calculados e eficientes, tais como os estudos de Bastos e Stephanou (2012), mostram:

A observação atenta desses artefatos, outrora de uso escolar, hoje objetos da memória familiar, possibilita mais do que o exame de uma materialidade ou dos processos de didatização do ensino da caligrafia e, portanto, dos temas de escrita e complexidade dos traçados. Também oportuniza uma reflexão acerca da produção de um determinado modo de ser e portar-se diante da escrita, particularmente como identidade do sujeito saudável e escolarizado. (p. 79)

Era variada a forma gráfica das letras constante nas páginas do periódico, pois havia escritos de várias autoras, todos registrados com letras bem caprichadas. Entretanto, não havia uma mesma tecnologia de registro: lápis para as alunas menores, $1^{\mathrm{a}}$ e $2^{\mathrm{a}}$ séries, e caneta tinteiro preta para as alunas maiores, da $3^{\mathrm{a}}$ e $4^{\mathrm{a}}$ séries. Tudo se apresentava limpo e sem rasuras, o que reforça a suposição de uma supervisão do colégio na confecção do 
material e mesmo na seleção dos textos. A correção gramatical evidencia uma preocupação com a língua vernácula, em um período em que a nacionalização do ensino se consolidava, notadamente no Sul do país. Também foi possível assinalar maior competência nas operações de cultura escrita entre as alunas mais velhas, $3^{\circ}$ e $4^{\circ}$ anos, pela ocupação mais equilibrada da página, pelo uso de termos mais elaborados e pelos níveis de alfabetização e domínio dos códigos escritos ${ }^{8}$.

As imagens de capa, linearmente dispostas, limitavam-se a desenhos que representavam cenas do universo infantil, quase sempre idealizadas e romantizadas, tais como paisagens bucólicas, meninas comportadas e bem vestidas, cercadas de flores e rodeadas por animais domésticos, que facilitavam a naturalizada aproximação entre o mundo animal e o mundo infantil. A presença de colagens de figuras de heróis nacionais e de santinhos religiosos, na concretude dos seus detalhes físicos, fazia jus ao ethos religioso do Colégio e dava o ritmo para a difusão de princípios de condutas cristãs, em que Deus era o centro de tudo.

Nos componentes icônicos são perceptíveis imagens e legendas sobre espírito de justiça, caridade para com os pobres, uma forma de fabricar sujeitos embebidos de valores católicos. Orações, cânticos religiosos e patrióticos, conselhos expressos em máximas e ditos populares reproduzidas nas páginas do jornal foram dando forma às ações pedagógicas e instauraram conselhos sobre ordem, limpeza, estética, higiene, bons comportamentos, formas de ser e modos de realizar também a evangelização e a formação espiritual das meninas sempre presentes em colégios confessionais. $\mathrm{Na}$ impossibilidade de reproduzir as capas, apresenta-se um quadro com os motivos escolhidos para cada capa das coleções anuais do jornal Pétalas Infantil.

Quadro 1

Motivos das capas da revista Pétalas Infantil (1945-1952).

\begin{tabular}{|c|c|c|}
\hline Ano & Número de páginas & Motivo da capa \\
\hline 1945 & 54 & Menina uniformizada/flores \\
\hline 1946 & 60 & Brincando com pétalas \\
\hline 1947 & 53 & Regando flores \\
\hline 1948 & 72 & Regando Flores \\
\hline 1949 & 60 & Regando Flores \\
\hline 1950 & 75 & Leitura em barco florido \\
\hline 1951 & 70 & Idem \\
\hline 1952 & 66 & Colhendo flores \\
\hline
\end{tabular}

Fonte: Acervo pessoal.

\section{O Pelotão de Saúde em Pétalas e a higienização da infância}

O objetivo do Pelotão de Saúde é inculcar hábitos e orientar a criança na aquisição de conhecimentos práticos, fornecendo-lhe um cabedal de costumes favorável à sua saúde. [...] Revestida de uma indumentária especial por ser infantil, nem por isso estará distante da realidade dos

\footnotetext{
${ }^{8} \mathrm{O}$ estilo redacional é rebuscado, com uso de adjetivação abundante e esta questão, com mais profundidade, será abordada no prosseguimento da pesquisa.
} 
fatos, encarando-os de frente e com a firmeza dos que desejam vencer. (Santa Catarina, 1946, p. 104).

O Pelotão de Saúde, denominado no Colégio Coração de Jesus como Clube Osvaldo Cruz, foi reiniciado em março de 1945, acontecimento registrado em uma página encimada pelo título SAÚDE! FORÇA! ALEGRIA! Este era o lema retirado da flâmula do Pelotão e cujo modelo estava contido na legislação de $1946^{\circ}$, que determinava que "a flâmula deveria ser de cor branca, tendo no canto inferior a cruz e este dístico também em letras vermelhas com trinta centímetros de lado menor e sessenta centímetros de comprimento" (Santa Catarina, 1946, p. 106). A ilustração aparecia no jornal, secundada pela expressão Clube Osvaldo Cruz e a notícia foi escrita nos seguintes termos.

Figura 2

Página do jornal Pétalas Infantil, 1945.

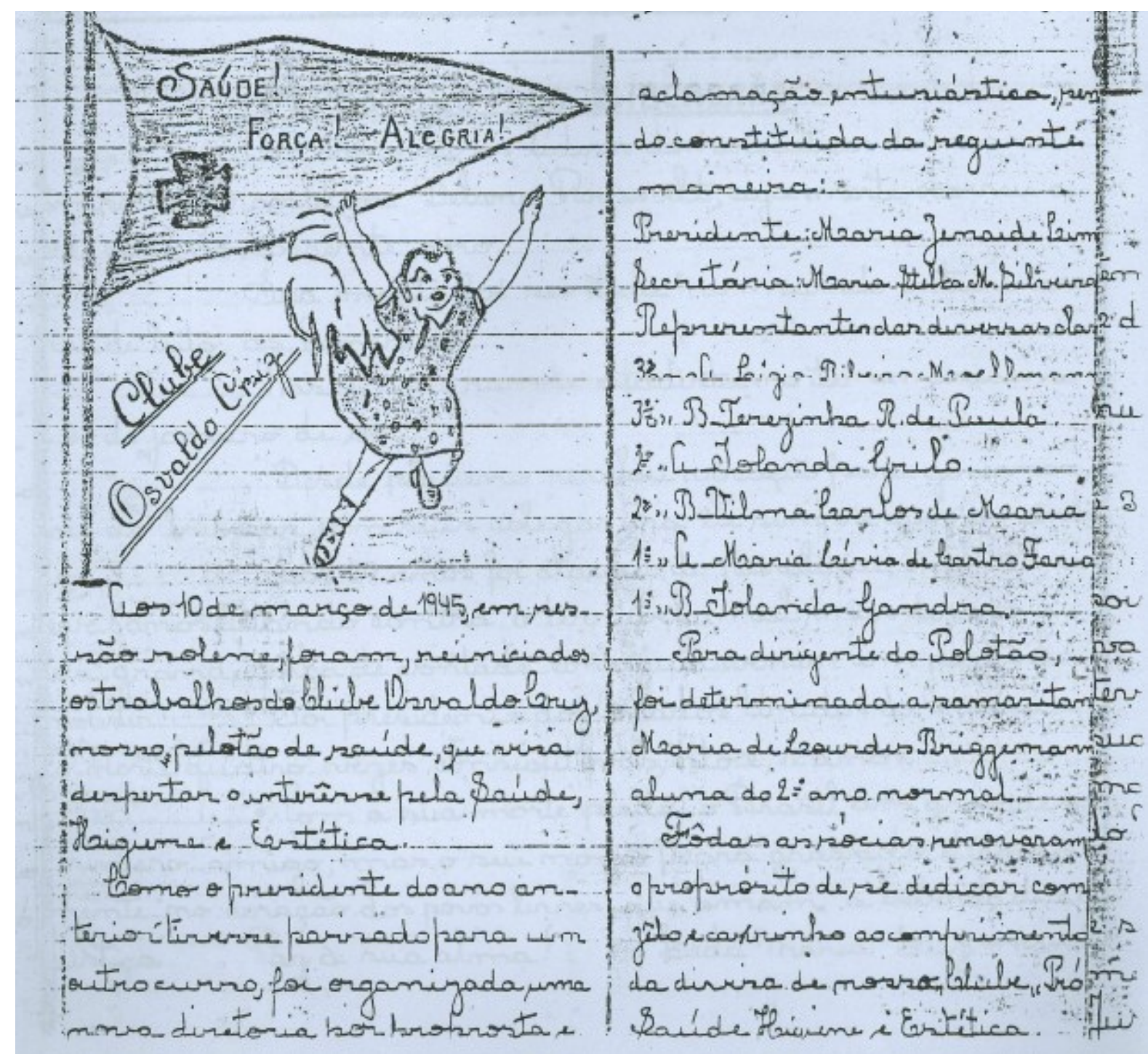

Fonte: Acervo da autora

\footnotetext{
${ }^{9}$ Art. 580, Item 11 op. cit. (1946).
} 
Aos 10 de março de 1945, em sessão solene, foram reiniciados os trabalhos do Clube Osvaldo Cruz, nosso Pelotão de Saúde, que visa despertar o interesse pela Saúde, Higiene e Estética. Como a presidente do ano anterior tivesse passado para um outro curso, foi organizada uma nova diretoria por proposta e aclamação entusiástica, sendo constituída da seguinte maneira:

Presidente: Maria Zenaide Lima

Secretária: Maria Stella M. Silveira

Representantes das diversas classes:

$3^{\circ}$ Ano A: Ligia Ribeiro Moellmann

$3^{\circ}$ Ana B: Terezinha R. de Paula

$2^{\circ}$ ano A: Iolanda Grilo

$2^{\circ}$ ano B: Vilma Carlos de Maria

$1^{\circ}$ ano A: Maria Lívia de Castro Faria

$1^{\circ}$ ano A: Iolanda Gandra

Para dirigente do Pelotão, foi determinada a samaritana Maria de Lourdes Briggemann, aluna do $2^{\circ}$ ano normal. Tôdas as sócias renovaram 0 propósito de se dedicar com zelo e carinho ao cumprimento da divisa de nosso Clube Pró Saúde, Higiene e Estética. (Pétalas Infantil, mar., 1945, p. 1)

O jornal Pétalas Infantil noticiava que a diretoria do Pelotão de Saúde era substituída sempre nos meses de março ou abril e havia a apresentação formal dos novos nomes e a fixação dos propósitos para aquele ano em curso. Em abril 1947 há o registro que "foram renovados os propósitos de dedicação e o cumprimento das obrigações dos deveres para com o Clube", (Pétalas Infantil, ago. 1947). Em agosto desse mesmo ano, um outro relatório anuncia que

desde que começou o ano letivo de 1947, nosso Clube entrou nas suas atividades. Meninas zelosas formam a sua diretoria. Elas cuidam para que tudo esteja na maior beleza e higiene possível. Fazemos mensalmente uma reunião, na qual tratamos dos assuntos mais úteis para o engrandecimento do "Clube Osvaldo Cruz". Assim é que procuramos tornar a escola, um ambiente de conforto, de saúde e de estética. Isto por meio dos preceitos higiênicos que damos á nossas coleguinhas e também pela beleza dos ornamentos de aula com flores. Assim sendo, nosso Pelotão contribui para o bem estar de todos. (Iponá Ribeiro, $3^{\circ}$ ano B Pétalas Infantil, ago., 1947)

Já em março de 1948, o jornal apresenta um longo texto intitulado Nossas associações, com a descrição das atividades realizadas no ano anterior por todas as associações existentes no Colégio:

No sábado, dia 20, foram eleitas, por aclamação as Diretorias para as diversas associações existentes no Curso Primário, para o ano de 1948. nos anos passados, estas associações muito contribuíram para a formação de boas maneiras e bons hábitos entre nossas colegas. A Liga da Bondade , muita sementinha do bem fez brotar nos nossos corações infantis, implantando neles a bela virtude da caridade. O Clube de Leitura nos instruiu com seus bons livros. Os atenciosos membros do Clube Osvaldo Cruz, muita vez nos socorreram quando dele precisávamos, contribuindo também com revisões e conselhos para a prática da higiene e estética entre nossas colegiais. Muita atividade desenvolveu a Liga Pró- 
Língua Nacional, que nos corrigia defeitos que habitualmente fazíamos na nossa bela língua, ensinando-nos assim a falar sempre mais corretamente a querida língua nacional. Queremos prosseguir com entusiasmo, esforçando-nos a tornar-nos sempre mais perfeitas no amor a Deus e a nossa querida Pátria. (Fernanda de C. Lobo $4^{\circ}$ ano A, Pétalas Infantil, mar., 1948)

Criar hábitos de ordem, incentivar a prática de princípios higiênicos, sugerir posturas corporais e trabalhar tais temas como fontes de beleza parece ter sido uma prática recorrente nas atividades do Pelotão de Saúde Clube Osvaldo Cruz, como se perceber em duas notícias veiculadas. Em junho de 1947, houve um comentário sobre a visita ao Colégio do inspetor escolar nos seguintes termos:

No sábado, dia 7, estivemos muito satisfeitas porque recebemos a visita do Sr. Inspetor. Fez-nos muitas perguntas e nós ficamos tão contentes porque sabíamos responder a todas. Ele viu nossos cadernos e ficou muito, muito satisfeito por causa da ordem e da letra bonita [...]. No fim da aula, cantamos. (Maria de Lourdes R. de Aguiar $3^{\circ}$ ano A, Pétalas Infantil, jun., 1947)

Em maio 1951 uma cronista, que não está identificada, realiza uma cronologia do mês, dia a dia. No espaço do dia 7 de maio escreve uma recomendação, anunciada pelo Pelotão de Saúde, que coloca em cena circunstâncias destinadas a fazer compreender uma lição, que tanto pode ser lida na clave da saúde como da estética, termo tão caro ao Clube:

A Associação Pelotão de Saúde - Clube Osvaldo Cruz - está iniciando o seguinte preceito: Não devemos usar blusas de lá no verão, falou-nos no pátio a Evangelia João Kotzias. (Pétalas Infantil, maio, 1951)

O nome do patrono do Pelotão de Saúde, Osvaldo $\mathrm{Cruz}^{10}$, segue uma proposta de cunho nacionalista ligada a vultos e heróis nacionais, no caso, vinculado à área da saúde. As alunas que compunham a diretoria do Pelotão de Saúde eram escolhidas nas três primeiras séries iniciais do curso primário e havia uma coordenação de uma futura professora primária, que aponta para expectativas de afirmação e continuidade do trabalho, partilhadas pela geração e pelo colégio.

O grupo eleito e aclamado ficava encarregado de promover e manter a higiene na Escola, entretanto não foram encontrados, nos exemplares estudados do jornal, aviso ou comentário que fosse de cunho fiscalizador ou denunciador. Tudo era apenas prescritivo e feito na base de sugestões, aconselhamentos sutis e pela transcrição de provérbios como $A$ exatidão no cumprimento dos deveres é perene fonte de alegria (jun., 1946), ou em forma de redações escolares, como se pode perceber numa redação que discorria sobre um dos lemas do Pelotão de Saúde do Colégio Coração de Jesus:

${ }^{10}$ Osvaldo Gonçalves Cruz (1872-1917) foi um cientista, médico, bacteriologista, epidemiologista e sanitarista brasileiro. É reconhecido como o patrono da medicina sanitarista, de base higienista, no Brasil. 


\section{Estética}

Estética é a ciência que trata do belo em geral. Dá-se o nome de estética às proporções exatas que devem existir em toda obra de arte, como por exemplo, na escultura, na pintura e nas decorações. [...] Não é só nas artes que a estética deve ser observada. Igualmente, o indivíduo pode apresentar-se com os sem estética. Os inestéticos (sic), isto é, as pessoas que tenham deformidades físicas, vícios de postura ou que sejam descuidadas na sua apresentação, podem melhorar o seu aspecto físico, a sua estética pela execução de um programa de ginástica, pelos bons hábitos de saúde e pela porta da indumentária em cuja confecção entre o bom gosto discreto e equilibrado. (Mary Alba Grisard, $4^{\circ}$ ano B, Pétalas Infantil, ago., 1946)

As palavras empregadas são exortativas e não oferecem espaços para erros; há preocupações com a saúde, com a postura do corpo e o uso das roupas. Os verbos empregados são mais prescritivos - devem - e os aconselhamentos denotam certeza do que se quer: agir, incutir, perseverar para melhorar. Assim, a infância, em nome provável de um desejo que não lhe é próprio, toma contato com leituras que visam a um disciplinamento. Foi nesta sociedade ordenada conforme as aspirações dos médicos, dos professores, dos legisladores que a preocupação com a saúde do corpo sadio e higienizado conectado com o ajuste disciplinar da criança se desenvolveu.

Ao longo da coleção de jornais em análise, as referências que as jovens alunas fazem do Pelotão de Saúde Clube Osvaldo Cruz seguem um protocolo bem particular, mais sutil e com mais ênfase na estética e que parece fugir das meras prescrições legislativas de limpeza pessoal. Os textos de orientação centram esforços na conjugação de elementos culturais que celebram a saúde em Conselhos úteis:

\section{Conselhos úteis}

Escove os dentes três vezes ao dia e procure o seu dentista duas vezes ao ano. Não use pós ásperos ou arenosos nos seus dentes. Não escove os dentes movendo a escova no sentido horizontal. (Acy Cordeiro $3^{\circ}$ ano A, Pétalas Infantil, set., 1946)

\section{Arremates: o pelotão narrado em Pétalas}

A força pela qual determinado artefato pode se impor aos nossos olhos abre margens para se pensar que não há uma essência evidente ou a ser procurada. Esse é o fundamento que se coloca quando o objeto assume a condição de documento histórico, matéria prima da interpretação histórica. Não é mais o objeto em si que interessa e sim o objeto em situação, ou seja, aquele que ganha forma e densidade na medida em que está em determinada situação. (Ramos, 2010)

Considerados como artefatos integrantes da educação escolarizada e reconhecidos como participantes do universo da cultura material escolar (Souza, 2008), os jornais ou impressos manuscritos escolares quase sempre se destinam ao lixo ou ao fogo. Salvos dessa sanha destruidora, estas escritas escolares produzidas por meninas alunas de um colégio religioso em Florianópolis, entre 1945 e 1952, chegaram até os dias de hoje para nos permitir construir história, ampliar a dimensão do conceito de documento e contribuir para a construção de uma narrativa que, pelas mãos do pesquisador/historiador, seja alvo de um controle do sentido. 
Este estudo permitiu um olhar aos fazeres escolares, ao colocar em evidência circunstâncias destinadas a fazer compreender as diferentes formas como o Colégio Coração de Jesus se apropriou dos preceitos legais relativos ao Pelotão de Saúde, menos em suas propostas higiênicas de fiscalização da salubridade e mais centrados nas propostas da lição moral, nos protocolos de civilidade que primavam pela ordem e pela estética, que podem ser interpretados como uma forma de demarcar a sua diferença social e sublinhar certo orgulho de seu universo de criação, uma sociabilidade desejada por aquela educação em um colégio de elite.

Componentes de uma cultura material escolar e trabalhadas na confluência da história da cultura escrita - aspetos gráficos, disposição geográfica do escrito - com a História da Educação - diferentes níveis de alfabetização, relato de fazeres cotidianos da escola, modalidades diferenciadas de apropriação das regras de bem escrever - a coleção de jornais constitui um acervo que marca um tempo e cria possibilidades para pensar em uma perspectiva ampliada de patrimônio cultural, capaz de sensibilizar estudiosos e instituições para a gestão e preservação desses materiais para a escrita da história da educação.

A partir deste estudo torna-se possível reforçar a hipótese de que o investimento do Colégio Coração de Jesus na formação e atuação do Pelotão de Saúde antecedeu a obrigatoriedade legal que foi determinada a partir de 1947. Dessa maneira, aponta vestígios escritos de como a aprendizagem da moral e da civilidade foi assumida por esta escola em termos de formação pessoal, cívica e religiosa.

Pôde-se perceber, nos vários textos escritos e copiados à mão, o investimento dispensado pela escola na composição de regimes de regras que pretendiam, ainda que em suportes ordinários, supervisionados pela direção e apresentados de forma ingênua, regulamentar e reforçar os costumes e as práticas culturais desejadas em infinitos matizes. Assim, pode-se afirmar que civilidade e infância estão ligadas e interligadas de maneira tenaz pela mediação da cultura escrita escolar, aqui representada pelos manuscritos e que, na educação escolarizada, faziam circular boas maneiras e hábitos morais elementares.

Procurou-se, igualmente, destacar a importância desse material manuscrito, analisando-o como um dos construtores da cultura material escolar e como uma das possibilidades de estudar a história das instituições escolares e os sentidos da educação feminina religiosa. As capas desenhadas, juntamente com artigos copiados, divulgavam propósitos visibilizados, principalmente em desenhos e cujas tarefas atribuídas às meninas estavam atreladas às atividades consideradas dons peculiares femininos por estarem, muitas vezes, relacionadas a afazeres domésticos.

Este esforço de interpretação, pelas lentes da História, constitui-se, também, em uma tentativa de apreender, por meio desse conjunto de textos, indícios de saberes e práticas escolares ligadas ao exercício das civilidades vigentes no período. 0 investimento nesta clave de pesquisa almeja colocar em cena o jornal como foco de difusão pedagógica de idéias, debates e propostas relacionadas às diversas formas de apresentação, iniciação e consolidação das práticas de escrita na escola.

Vencidos pelo tempo, estes manuscritos infantis conservam registros de meninas alunas que construíram, pela escrita, um lugar de memória para suas experiências 
escolares as quais, por terem chegado até nós depois de sessenta anos, são motivo de maravilhamentos e perturbações. Instáveis e incertas, as práticas de escrita sobre a forma caligráfica, como elementos de uma cultura material da escola, certamente podem produzir outros sentidos para além dos aqui discutidos.

\section{Referências}

BASTOS, Maria Helena Camara. As revistas pedagógicas e a atualização do professor: a Revista do Ensino do Rio Grande do Sul (1951-1992). In. Catani, Denice Barbara e BASTOS, Maria Helena Camara. Educação em revista: a imprensa periódica e a história da educação. São Paulo: Escrituras, 1997, p. 47-75.

BASTOS, Maria Helena Camara; STEPHANOU, Maria. Da sensibilidade das mãos à harmonia da escrita: memórias, artefatos e gestos da caligrafia na história da educação. In: TRINCHÃO, Gláucia Maria da (org.). A caligrafia e a escrita: do desenho das belas letras à livre expressão do desenho da escrita. Feira de Santana: UFS, 2012.

CARVALHO, Marta. Molde nacional e fôrma cívica: higiene, moral e trabalho no projeto da Associação Brasileira de Educação. (1924-1931). Bragança Paulista: USF, 1998.

CASTILLO GÓMES, António (coord.). Historia de la cultura escrita: del Próximo Oriente Antiguo a la sociedad informatizada. Madrid: Trea, 2002.

CASTILLO GÓMES, António; SIERRA BLAS, Verónia. Mis primeros passos: alfabetización, escuela y usos cotidianos de la escritura (siglos XIX y XX). Madrid: Trea, 2008.

CHARTIER, Roger. A história cultural: entre práticas e representações. Lisboa: Difel, 1989.

COSTA, Jurandir Freire. Ordem médica e norma familiar. Rio de Janeiro: Graal, 1999.

CUNHA, Maria Teresa Santos. Mensageiro de sociabilidades: estudo sobre um jornal escolar infantil (Florianópolis, 1946-1952). In: MORGA, Antônio. História, cidade e sociabilidade. Itajaí: Casa Aberta, 2011, p. 235-250.

DECRETO n. 3735, de 17 de dezembro de 1946. Regulamento para os estabelecimentos de ensino primário no Estado de Santa Catarina. Florianópolis, Imprensa Oficial, 1946.

FIORI, Neide Almeida. Aspectos da evolução do ensino público: ensino público e política de assimilação cultural no Estado de Santa Catarina nos períodos Imperial e Republicano. Florianópolis: UFSC/Secretaria da Educação do Estado de Santa Catarina, 1991.

GALVÃO, Ana Maria de Oliveira (org.). História da cultura escrita: séculos XIX e XX. Belo Horizonte: Autêntica, 2007.

HEINZ, Flávio M. (org.). Por uma outra história das elites. Rio de Janeiro: FGV, 2006.

JORNAL INFANTIL PÉTALAS. (Manuscrito). Colégio Coração de Jesus. Exemplares de 1945,1946, 1947, 1948, 1950, 1951 e 1952.

MIGNOT, Ana Chrystina Venâncio (org.). Cadernos à vista: escola, memória e cultura escrita. Rio de Janeiro: Uerj, 2008.

PERES, Eliane; TAMBARA, Elomar (orgs.). Livros escolares e ensino da leitura e da escrita no Brasil (séculos XIX e XX). Pelotas: Seiva, 2003.

RAMOS, Francisco Régis Lopes. As utilidades do passado na biografia dos objetos. In: GUIMARÃES, Manoel Luiz Salgado; RAMOS, Francisco Régis Lopes (org.). Futuro do 
pretérito: escrita da história e história do museu. Fortaleza: Instituto Frei Tito Alencar, 2010.

REVISTA DO ENSINO/RS. Maio, 1952, n. 6.

REVISTA PÉTALAS. Colégio Coração de Jesus. Florianópolis: Tipografia dos Artífices. 1933.

ROCHA, Heloisa Helena Pimenta. Prescrevendo regras de bem viver: cultura escolar e racionalidade científica. Cadernos Cedes, Campinas: Unicamp, n. 52, 2000, p. 55-73.

SOUZA, Rosa Fátima. Templos de civilização: a implantação da escola primária graduada no estado de São Paulo (1890-1910). São Paulo: Unesp, 1998.

SOUZA, Rosa Fátima. História da cultura material escolar: um balanço inicial. In: BENCOSTTA, Marcus Levy (org.). Culturas escolares, saberes e práticas educativas: itinerários Históricos. São Paulo: Cortez, 2008, p. 163-191.

VIDAL, Diana Gonçalves; GVIRTZ, Silvina. O ensino da escrita e a conformação da modernidade escolar: Brasil e Argentina, 1880-1940. Revista Brasileira de Educação, São Paulo: Anped, n. 8, 1998, p. 13-30.

VINÃO FRAGO, Antonio. Leer y escribir. historia de dos practicas culturales. México: Voces y Vuelos, 2002.

MARIA TERESA SANTOS CUNHA é professora no Departamento de História da Universidade do Estado de Santa Catarina, na área de Patrimônio Cultural, e nos programas de pós-graduação em Educação e História. Bolsista produtividade em pesquisa do CNPq.

Endereço: Rua Prof. Marcos Cardoso Filho, 108 - 88037-040 - Florianópolis - SC Brasil.

E-mail: mariatsc@gmail.com. 